Article

\title{
Survey and Photogrammetric Restitution of Monumental Complexes: Issues and Solutions-The Case of the Manfredonic Castle of Mussomeli
}

\author{
Andrea Scianna ${ }^{*}+\left(\mathbb{D}\right.$ and Marcello La Guardia ${ }^{\dagger}$ \\ ICAR-CNR (High Performance Computing and Networking Institute-National Research Council of Italy) at \\ GISLab c/o D'Arch, Polytechnic School of University of Palermo, 90128 Palermo, Italy; \\ marcellolaguardia87@libero.it \\ * Correspondence: andrea.scianna@cnr.it \\ t These authors contributed equally to this work.
}

Received: 4 February 2019; Accepted: 25 February 2019; Published: 28 February 2019

\begin{abstract}
The latest results obtained through photogrammetric restitution enhanced by GNSS (Global Navigation Satellite System) RTK (Real-Time Kinematic) survey achieved increased levels of accuracy. These survey solutions are used to rapidly obtain a detailed model with an excellent level of accuracy (centimetric) with cheaper equipment. However, the contour conditions are not always favorable for obtaining the best results in a simple way. The work presented in this paper shows the survey and the photogrammetric restitution of the Manfredonic Castle of Mussomeli in Sicily, developed as a part of the PON NEPTIS European Project, aimed at the valorization of Cultural Heritage $(\mathrm{CH})$. This case is a typical example of a complex survey carried out in an impervious environment where traditional survey procedures are totally useless or require a longer amount of time and great effort if a high level of accuracy is requested. In this case, considering the natural conditions of the site, the only way to perform the task has been the use of photogrammetric restitution based on UAV (unmanned aerial vehicle) technologies and GNSS survey. The precision obtained from the results allowed us to create a geometric 3D reconstruction of the monumental complex of the castle for the valorization of the site, which was the main goal of the whole process. The procedure that is the focus of this work is a test of rapid 3D CH survey and documentation in an impervious environment.
\end{abstract}

Keywords: $\mathrm{CH}$; UAV; monumental complex; photogrammetry; survey; 3D model

\section{Introduction}

Topographic technologies and methodologies have always been necessary for the protection, safeguarding, and fruition of archaeological sites and monumental complexes, as well as for geological analysis for the purpose of hazard assessment [1]. The use of these instruments encounters real difficulties in survey operations; these operations usually characterize monumental complexes where problematic access to places, the state of degradation of the structures, and difficulty identifying the ruins are typical elements of the operations in situ. For this reason, sometimes it is necessary to solve these issues by developing specific strategies regarding surveys that differ from the procedures generally followed for simpler scenarios.

In fact, multi-image photogrammetry has become a crucial archaeological tool because it is a methodology less expensive than the standard procedures that use a laser scanner [2] and because it allows an acceptable level of precision in the restitution. Indeed, this technology allowing the reconstruction of the 3D environment has become very useful for the 3D documentation of Cultural Heritage $(\mathrm{CH})$ [3]. Recently, the increasing diffusion of unmanned aerial vehicle (UAV) systems for 
many survey applications $[4,5]$ has also added fundamental value to photogrammetric solutions for archaeological surveys.

The use of aerial acquisition allows us to achieve the restitution of an impervious and complex environment that would be unavailable using standard topographical equipment on the ground [6]. The study case in this work-the survey and the restitution of the Manfredonic Castle of Mussomeli-led us to choose this technology in light of the limits related to the short time available for survey operations, the complex orographic shape of the site, and adverse natural conditions. These difficulties contributed added value to the goal of this work (that is, the valorization of the Castle of Mussomeli and the surrounding environment), making the reconstruction of the monument and the natural surrounding context an interesting challenge to overcome.

\section{Preliminary Analysis of the Site: The Manfredonic Castle of Mussomeli}

The choice of the best solution to adopt during survey operations strongly depends on the main features of the considered historic or archaeological site. In particular, the Manfredonic Castle of Mussomeli (built in 1374 in Sicily by Manfredi Chiaramonte) represents an example of a monumental complex strongly connected with the natural environment around it. The castle dominates a wide surrounding area, thanks to the strategic position of its settlement.

It is located on the top and inside of a massive rock, with some complementary structures situated around the north side of it. The rock presents an extension of about $250 \times 150 \mathrm{~m}$ on the ground and is about $85 \mathrm{~m}$ in height from the base level (Figure 1).

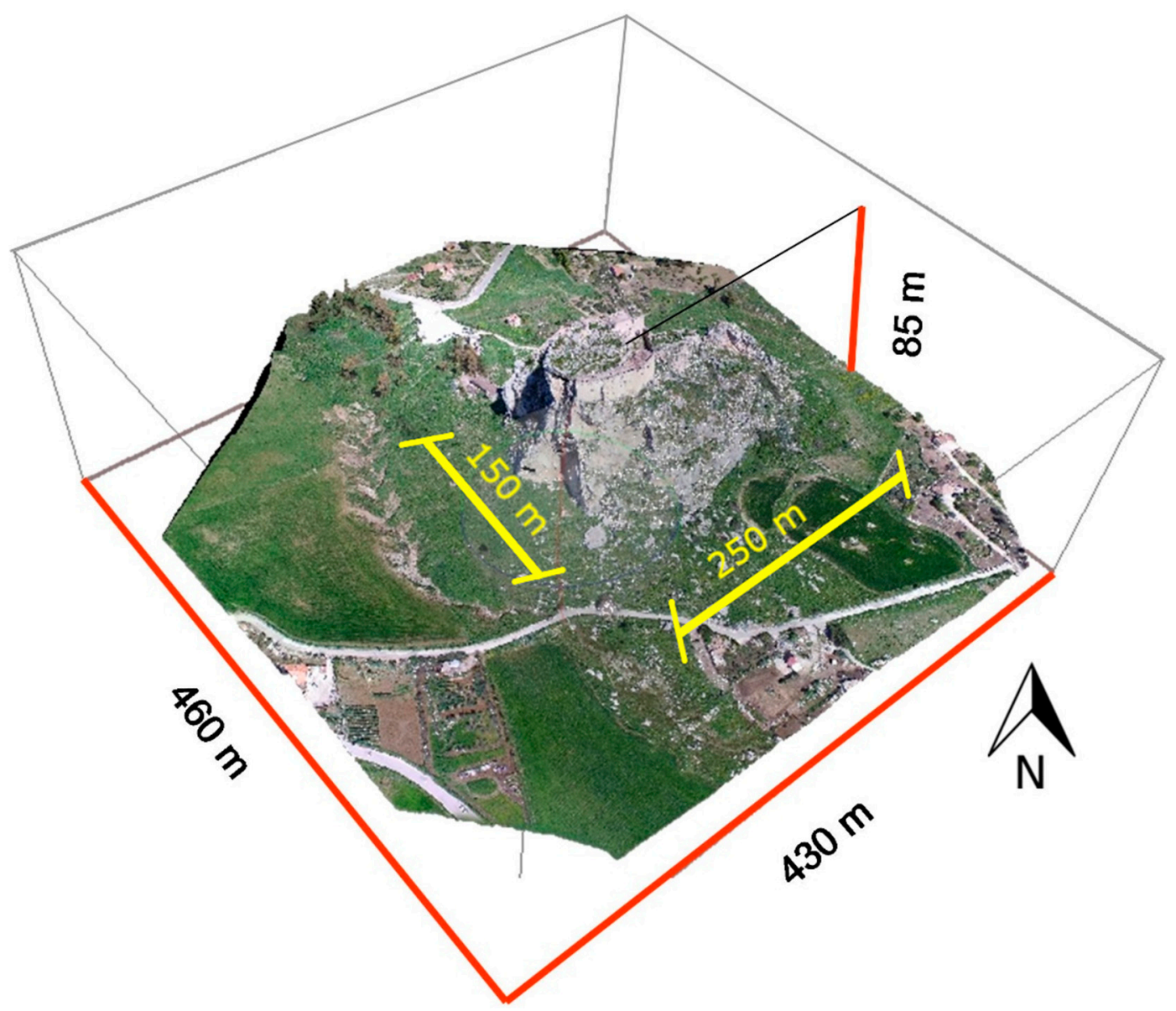

Figure 1. The surveyed area and its dimensions.

On the south side, the rock emerges the surrounding landscape, and nobody could climb from that side. The only climbing path available exists on the north side, where the system of walls guarantees a 
less impervious trek from the main entrance to the top of the rock (Figure 2). The central courtyard and the main buildings of the castle are settled on the top of the rock.
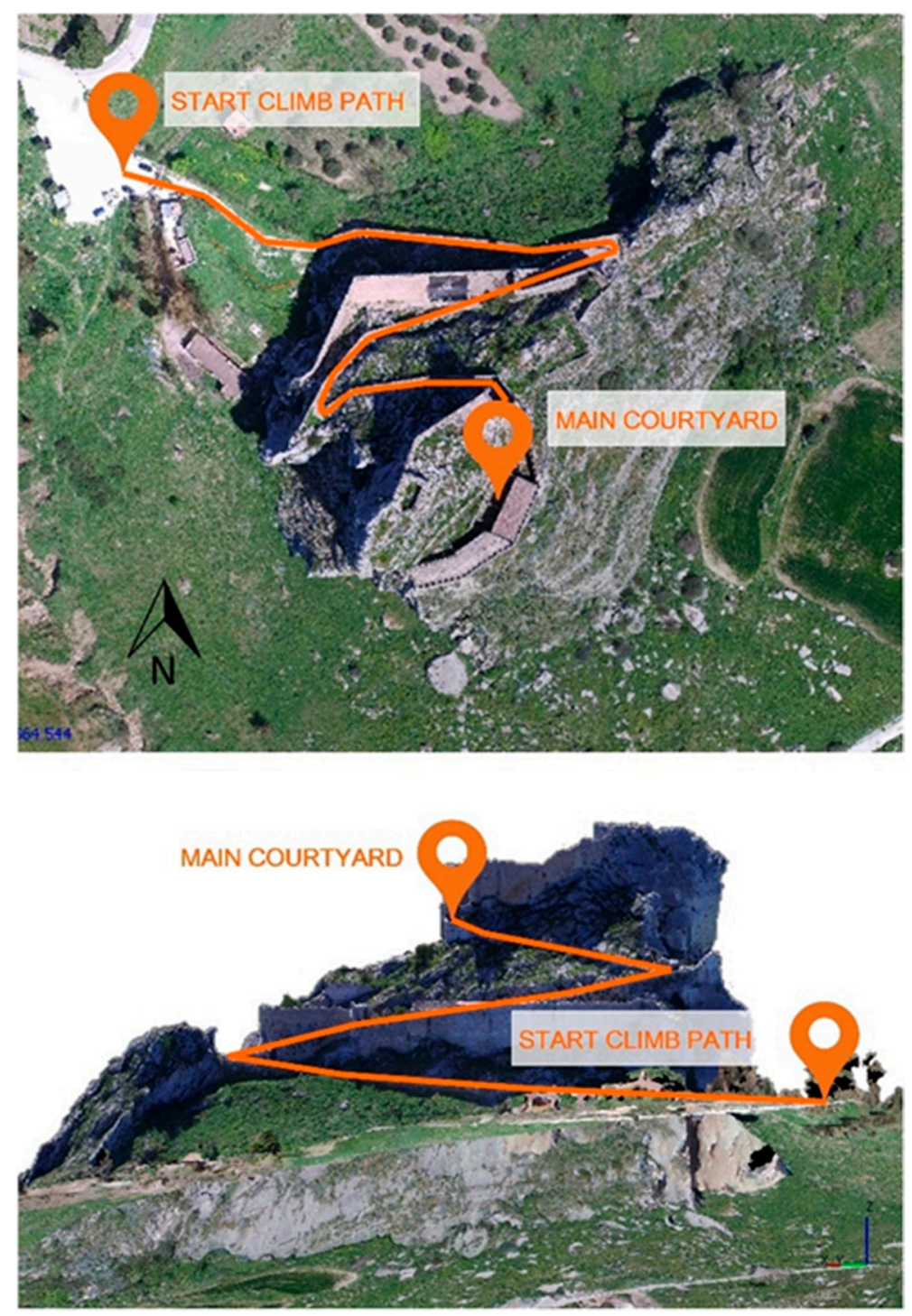

Figure 2. The climbing path (in orange) seen in horizontal and vertical projections.

Constant wind characterizes the weather conditions all around the rock (from 6 to $15 \mathrm{~m} / \mathrm{s} \mathrm{speed);}$ this is probably caused by the orographic position, because there are no mountains in the neighboring area that could protect the site. Hence, the difficulty of access and the adverse orographic and climatic conditions make the Castle of Mussomeli an interesting case for experimentation with innovative survey operations in impervious areas.

\section{The Survey Operations}

The model of the castle was realized by 3D photogrammetric reconstruction of the outdoor environment (facades, roofs, and open spaces) and indoor spaces and rooms (Figure 3). The primary aim of this last procedure was the creation of an image-based reconstruction useful for virtual tourism applications [7]. 


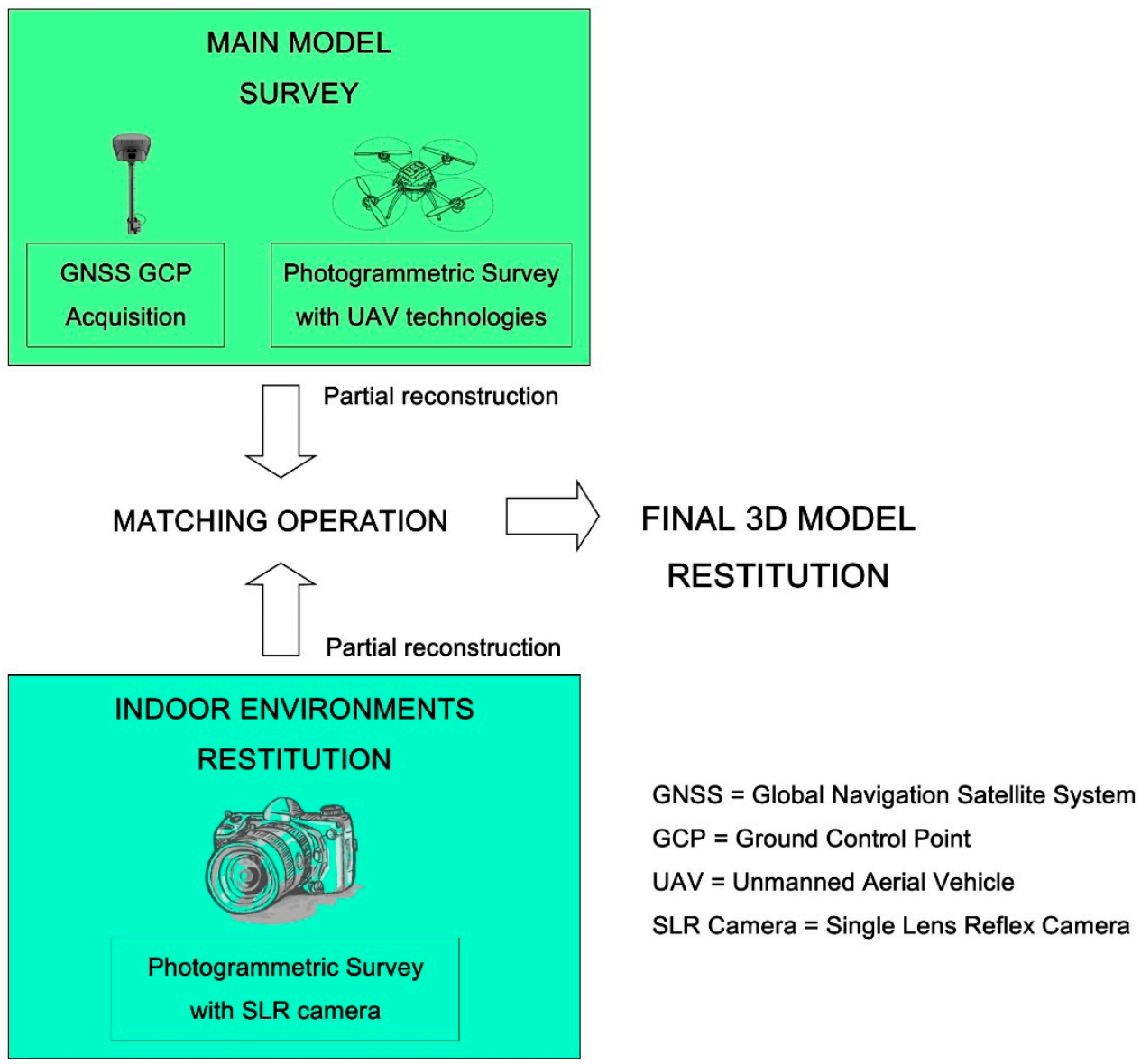

Figure 3. The procedure followed for the restitution.

In particular, the photogrammetric solution allows us to obtain a 3D model with an acceptable accuracy and sufficient LoD (Level of Detail) to create a virtual reconstruction useful for the sharing of $\mathrm{CH}$ information and for the purpose of the touristic fruition of the castle.

From the beginning of this work, the idea of using ground survey equipment like laser scanners was discarded due to the particular position of the castle. Indeed, the natural conditions obliged us to use UAV survey and photogrammetric restitution supported by the acquisition of natural ground control points. The primary target of this operation was the creation of a 3D virtual reconstruction of the monumental complex for touristic fruition and documentation, with reduced time spent on survey operations.

Considering UAV survey operations, the strong and constant presence of the wind required the execution of multiple flights with crossed trajectories over the top of the rock, far from rocky walls. In fact, the idea of making flights around the rocky wall was rejected because of the variable wind conditions around all sides that could alter the stability of the drone, increasing the possibility of a crash. Another critical issue to solve was the choice of the best location of the base camp for the take-off and landing of the UAV. In fact, the take-off and landing point of the UAV should be high enough and with enough free space around in order to take advantage of an open view of the sky to guarantee the best acquisition of the Global Navigation Satellite System (GNSS) position. For these reasons, the flight plan was set up by choosing the central courtyard of the castle as a base camp and programming a flight height of $70 \mathrm{~m}$ over the take-off area (Figure 4). 


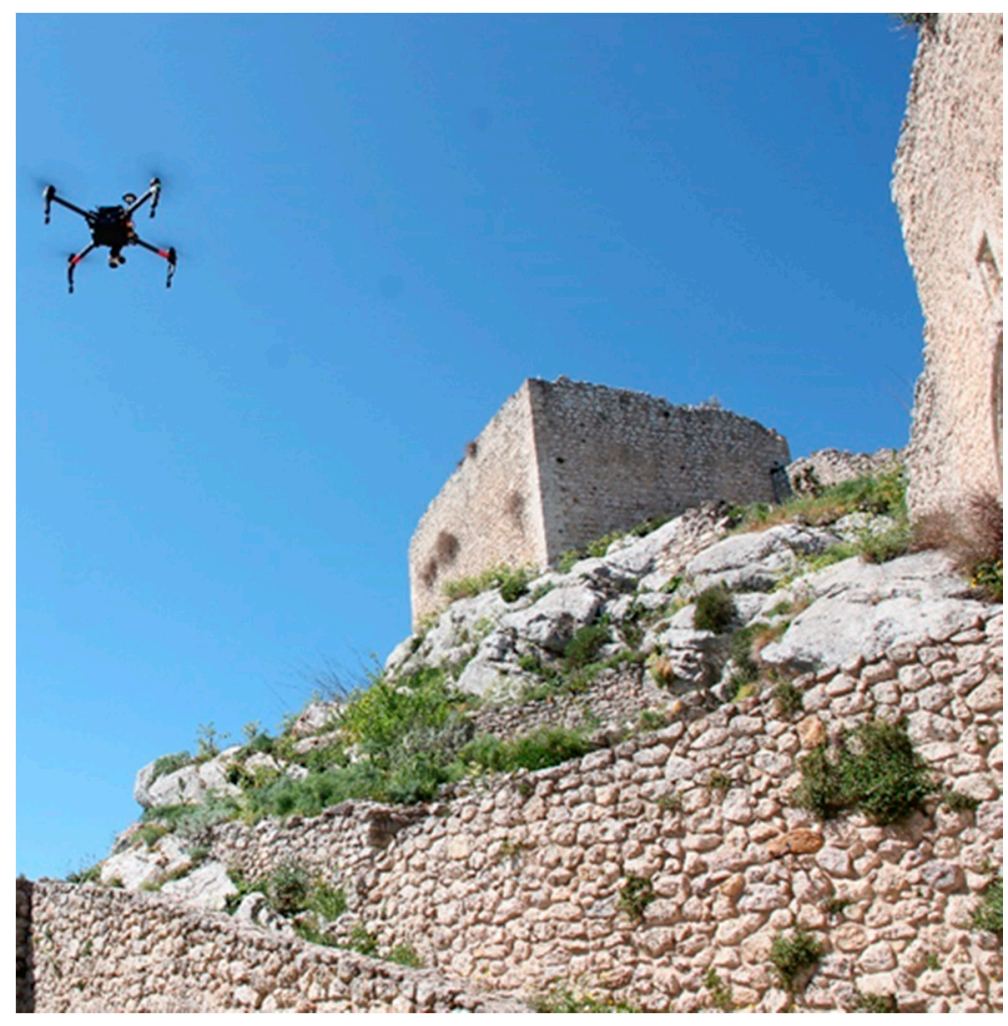

Figure 4. The UAV landing inside the courtyard of the castle.

To produce an exhaustive photogrammetric restitution, two flights were chosen from all flights executed: one with the camera in nadiral position, and another with the camera $45^{\circ}$ degrees inclined. For the flights, a DJI Matrice 100 quadcopter was used with a Zenmuse X3 onboard camera. The resolution of the camera was 12 Megapixels with a $3.6 \mathrm{~mm}$ focal length. The Ground Sampling Distance (GSD) varied according to the elevation of the terrain surface (Table 1).

Table 1. Survey camera data.

\begin{tabular}{cc}
\hline \multicolumn{2}{c}{ Zenmuse X3 Camera } \\
\hline Sensor size & $6.17 \times 4.55 \mathrm{~mm}$ \\
Resolution & $4000 \times 3000$ \\
Focal length & $3.6 \mathrm{~mm}$ \\
Eq. Focal length & $20 \mathrm{~mm}$ \\
GSD (Ground Sampling Distance) at entrance square & $5 \mathrm{~cm} / \mathrm{px}$ \\
(120 m distance) & \\
GSD (Ground Sampling Distance) at main courtyard & $2.91 \mathrm{~cm} / \mathrm{px}$ \\
(70 m distance) & $0.214 \mathrm{~m}$ \\
Average error & 24 \\
\hline
\end{tabular}

At the same time, a GNSS Real-Time Kinematic (RTK) survey of 24 targets was performed considering visible and recognizable natural points, taken along the only accessible climbing path of the castle (Figure 5a,b and Figure 6). During this operation, the level of accuracy of the GNSS signal was threatened by the natural conditions of the site. Indeed, positioning the GNSS station close to the walls of the castle, we noticed a reduction in signal precision caused by the multipath phenomenon. Furthermore, the presence of the massive rock that hid a relevant portion of the sky dome reduced the number of visible satellites and, hence, the accuracy of the GNSS signal. 


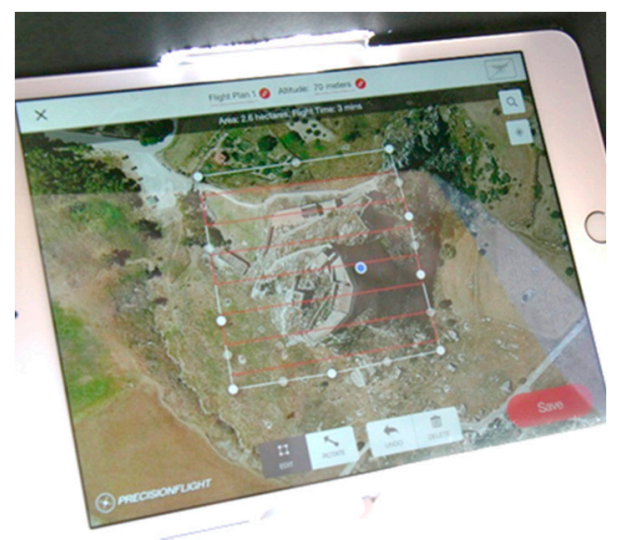

(a)

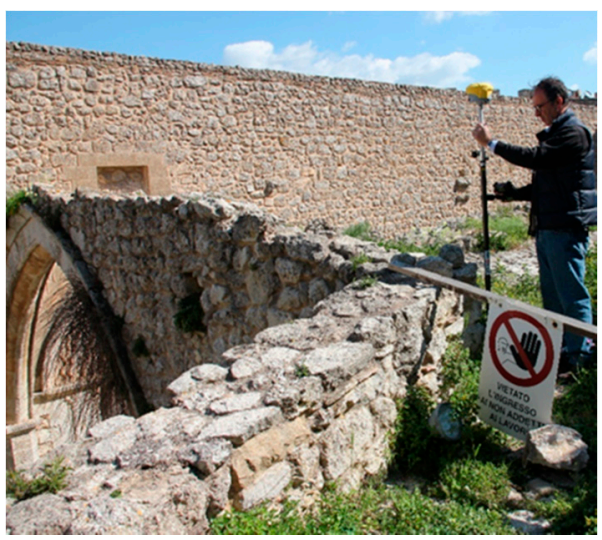

(b)

Figure 5. (a) The flight plan monitored on a tablet; (b) GNSS survey operations.

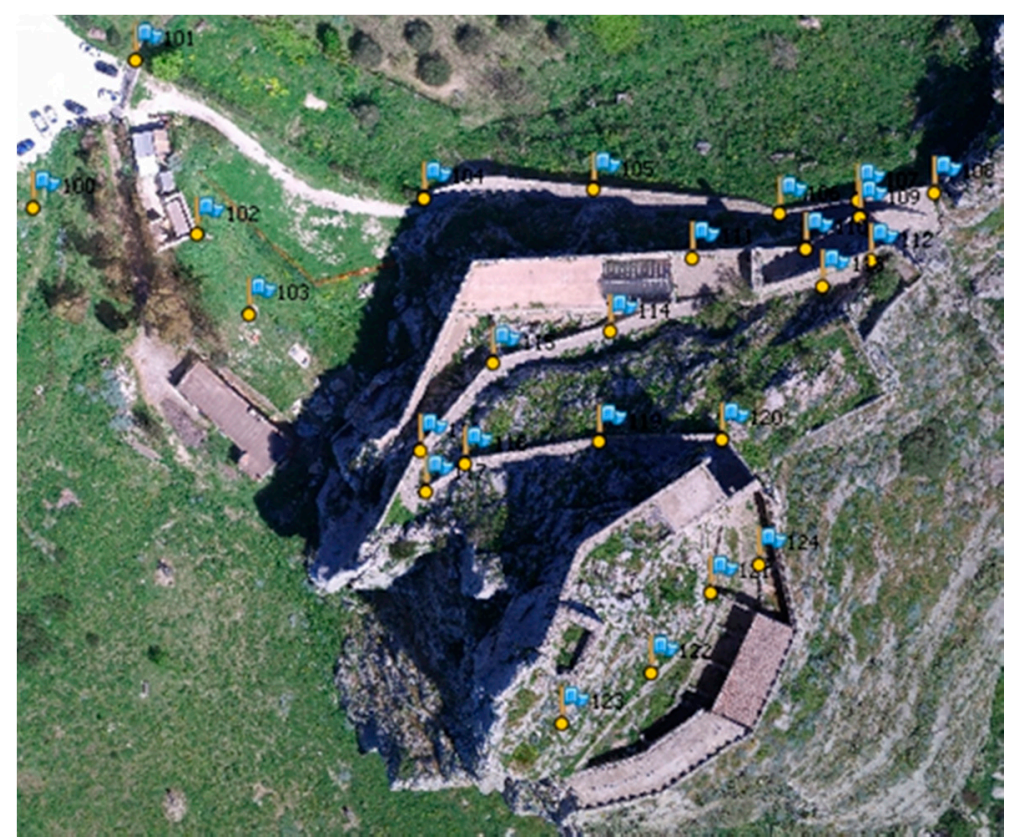

Figure 6. This orthophoto of the castle with the indication of GNSS markers was generated considering the DTM (Digital Terrain Model) produced by the photogrammetric reconstruction improved by the GNSS network. The starting DTM reference was the Sicilian Region 2 m DTM.

At the same time, a multi-image photogrammetric survey of every room was acquired for the reconstruction of the indoor environments. During these operations, we used an SLR (Single Lens Reflex) Canon 550D camera with a resolution of 18 Megapixels. In this phase the camera was positioned on different station points inside every room in order to acquire sufficiently many images taken from different angles, ensuring the coverage information necessary for the full reconstruction of the environments.

\section{From the Point Cloud to the Restitution of the Model}

Once we had executed the GNSS and photogrammetric survey, the SFM (Structure from Motion) algorithm was used for the construction of the point clouds of the indoor and outdoor environments. This technology allows the reconstruction of the point cloud using a dataset of photos that captures the surfaces from different points of view [8]. Indeed, with the recent achievements in computer and information technologies, traditional procedures for survey operations have been increasingly replaced with digital close-range photogrammetry [9]. In particular, the reconstruction of the point cloud is 
obtained using an algorithm that defines a probability distribution of the structure using step-by-step iteration [10].

Agisoft Photoscan ${ }^{\circledR}$ software was used for the creation of the point clouds (Figure 7) and the restitution of the 3D models. During the processing of the outdoor environment, the flight datasets of both a 45-degree-inclined camera and a nadiral position camera were used. After a pre-alignment operation choosing parameters for a high level of accuracy, markers with the coordinates of 24 GNSS targets were loaded into the project in order to match every visible marker on every image. The flight plan was programmed considering a $70 \mathrm{~m}$ flight height over the take-off surface, obtaining a GSD (ground sampling distance) of $2.91 \mathrm{~cm} / \mathrm{px}$, according to the features of the camera. This GSD value is relative to the level of the central courtyard of the castle (the higher zone of the site). Instead, considering the entrance square, positioned at the base of the climbing path (with a $120 \mathrm{~m}$ flight height) the GSD achieved a value of about $5 \mathrm{~cm} / \mathrm{px}$ (Figure 8).

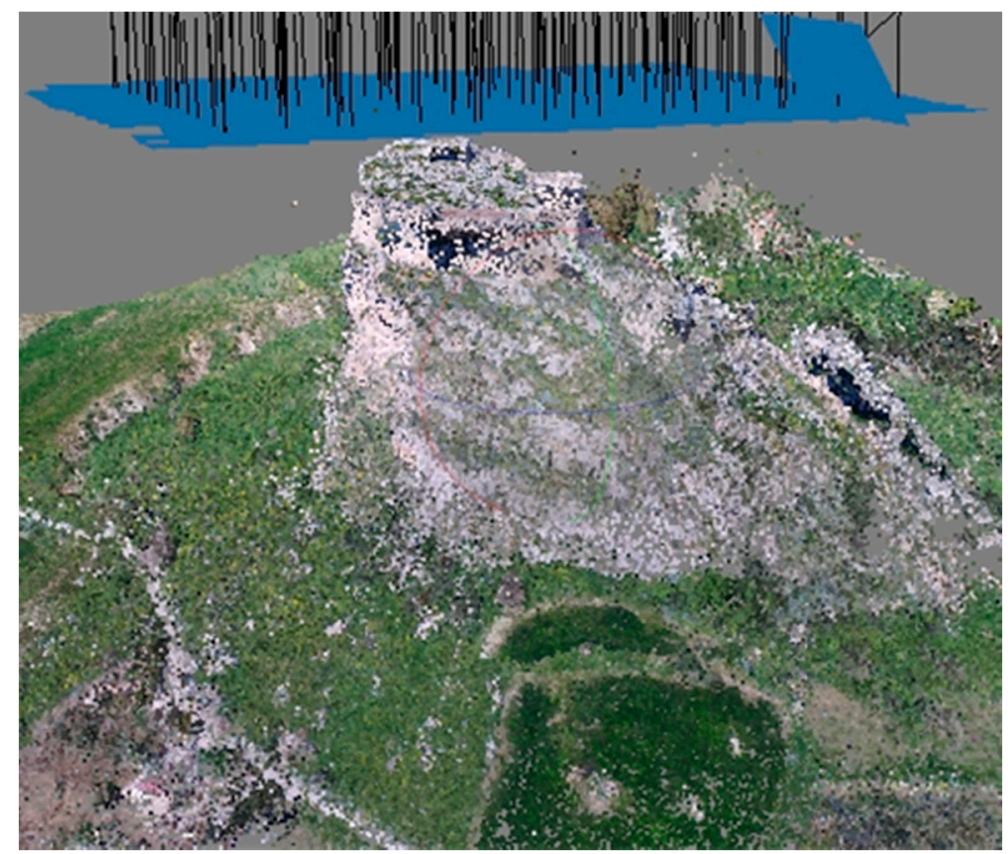

Figure 7. The starting sparse point cloud of the surveyed area.

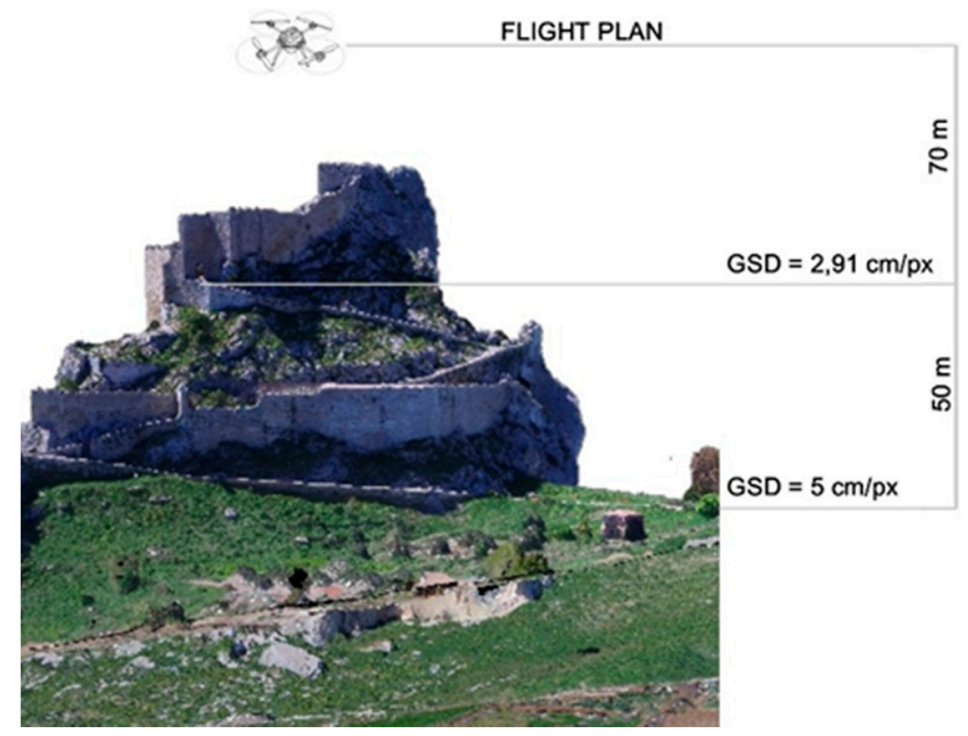

Figure 8. The vertical distances and the GSD range. 
As affirmed before, the GSD values changed along the climbing path due to the strong inclination of the site and the irregular shape of the terrain that produced strong variations in the vertical distance from the UAV.

The most accurate result was achieved using only the dataset of 142 images obtained from the 45-degree-inclined camera; however, this was strongly influenced by the adverse natural conditions of the site. In particular, the obtained level of accuracy of the considered GNSS RTK network ranged between $0.088 \mathrm{~m}$ and $0.432 \mathrm{~m}$, achieving a total error of $0.214 \mathrm{~m}$ (Figure 9). This value was obtained by discarding five targets that possessed a larger GNSS error of accuracy and represents an exhaustive result considering the strongly irregular shape of terrain, the presence of multiple paths, the reduced number of visible satellites, and the impossibility of producing a more distributed GNSS network of the target due to inaccessibility of the surroundings. The final dataset was used to create the point cloud of the outdoor environment.

\begin{tabular}{|c|c|c|c|c|c|c|}
\hline Markers & Easting & Northing & Altitude & Error $(\mathrm{m})$ & Projections & Error (pix) \\
\hline$\nabla \omega 100$ & 391409.737000 & 4159705.324000 & 703.935000 & 0.000000 & 0 & 0.000 \\
\hline$\square \mathbb{P} \forall 101$ & 391428.714000 & 4159732.187000 & 704.748000 & 0.375187 & 30 & 13.053 \\
\hline$\square$ 田 102 & 391440.179000 & 4159700.479000 & 707.690000 & 0.235535 & 45 & 2.445 \\
\hline$\square \mathbb{P} 104$ & 391482.036000 & 4159707.275000 & 708.797000 & 0.253487 & 42 & 2.550 \\
\hline$\square \mathbb{P} 105$ & 391513.619000 & 4159708.573000 & 711.151000 & 0.000000 & 0 & 0.000 \\
\hline$\square \mathbb{V} 106$ & 391548.179000 & 4159704.287000 & 713.674000 & 0.431987 & 15 & 2.199 \\
\hline$\square \mathbb{B} 107$ & 391562.738000 & 4159706.444000 & 716.229000 & 0.000000 & 0 & 0.000 \\
\hline$\square \mathbb{P} 108$ & 391576.762000 & 4159708.143000 & 717.184000 & 0.395294 & 5 & 2.112 \\
\hline$\square[109$ & 391563.098000 & 4159703.437000 & 719.884000 & 0.116323 & 15 & 3.978 \\
\hline 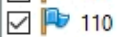 & 391553.209000 & 4159697.712000 & 723.211000 & 0.088852 & 13 & 2.433 \\
\hline$\square[111$ & 391531.997000 & 4159696.111000 & 725.560000 & 0.157291 & 14 & 1.489 \\
\hline$\square \mathbb{P} \geqslant 112$ & 391565.331000 & 4159695.460000 & 727.061000 & 0.000000 & 0 & 0.000 \\
\hline$\square \mathbb{1} 113$ & 391556.424000 & 4159690.839000 & 727.289000 & 0.000000 & 0 & 0.000 \\
\hline$\square$ 回 114 & 391516.773000 & 4159682.227000 & 730.418000 & 0.000000 & 0 & 0.000 \\
\hline$\square \mathbb{P} 116$ & & & & & 46 & 3.440 \\
\hline$\square \mathbb{P} 117$ & & & & & 48 & 3.610 \\
\hline$\square \mathbb{P} 118$ & & & & & 34 & 3.061 \\
\hline$\square \mathbb{V} 119$ & 391515.294000 & 4159661.919000 & 748.068000 & 0.178907 & 29 & 7.040 \\
\hline$\square \mathbb{P} 120$ & 391537.422000 & 4159661.820000 & 752.676000 & 0.470203 & 31 & 4.209 \\
\hline$\square \mathbb{\nabla} 121$ & 391535.240000 & 4159633.814000 & 758.374000 & 0.285006 & 26 & 4.076 \\
\hline 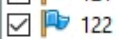 & 391524.250000 & 4159619.160000 & 760.835000 & 0.247042 & 25 & 3.393 \\
\hline$\square \square 123$ & 391507.948000 & 4159609.765000 & 769.519000 & 0.508835 & 17 & 3.893 \\
\hline$\square \mathbb{P} 124$ & 391544.251000 & 4159639.422000 & 754.257000 & 0.317659 & 23 & 2.946 \\
\hline Total Error & & & & 0.214742 & & 3.640 \\
\hline
\end{tabular}

Figure 9. Errors and accuracy of the survey restitution.

The reconstruction of the outdoor point cloud was the base for the creation of the 3D mesh of the entire monumental complex including the natural environment around it. At the same time, with the same technology, the point clouds of indoor environments of the castle (the baron's hall, the bedroom, the chapel, etc.) were created (Figure 10a,b). In particular, a realistic 3D restitution of every interior room was developed by considering a huge number of photos taken from different angles and different positions and with some main distances as a reference but without the support of the GNSS network. The level of precision obtained from this operation was satisfactory in relation to the primary goal of this 3D restitution: the creation of a realistic 3D model of the castle with a good level of detail, useful for a virtual tourism application and documentation, and developed using fast survey operations with a reduced number of operators. 


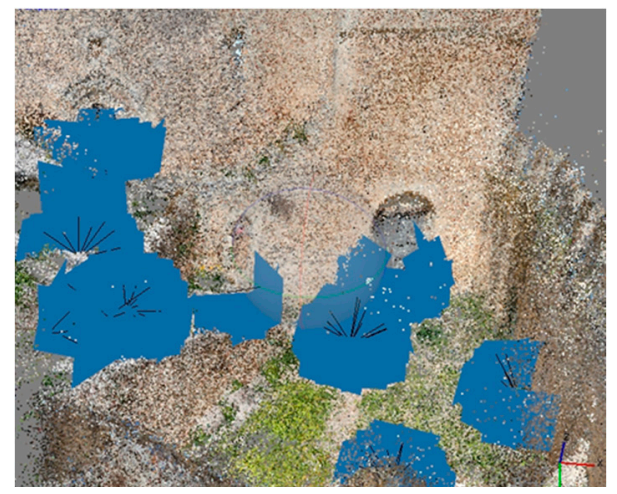

(a)

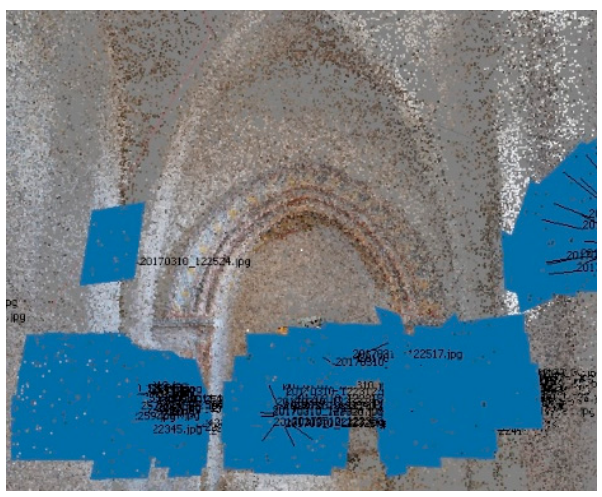

(b)

Figure 10. (a) An outdoor view of the sparse cloud of the courtyard; (b) An indoor view of the sparse cloud of the chapel.

Furthermore, this 3D restitution (Figure 11) could grant access to all of the main environments (outdoor and indoor), matching the cloud with an outdoor topographic reference network guaranteed by the presence of GNSS markers.

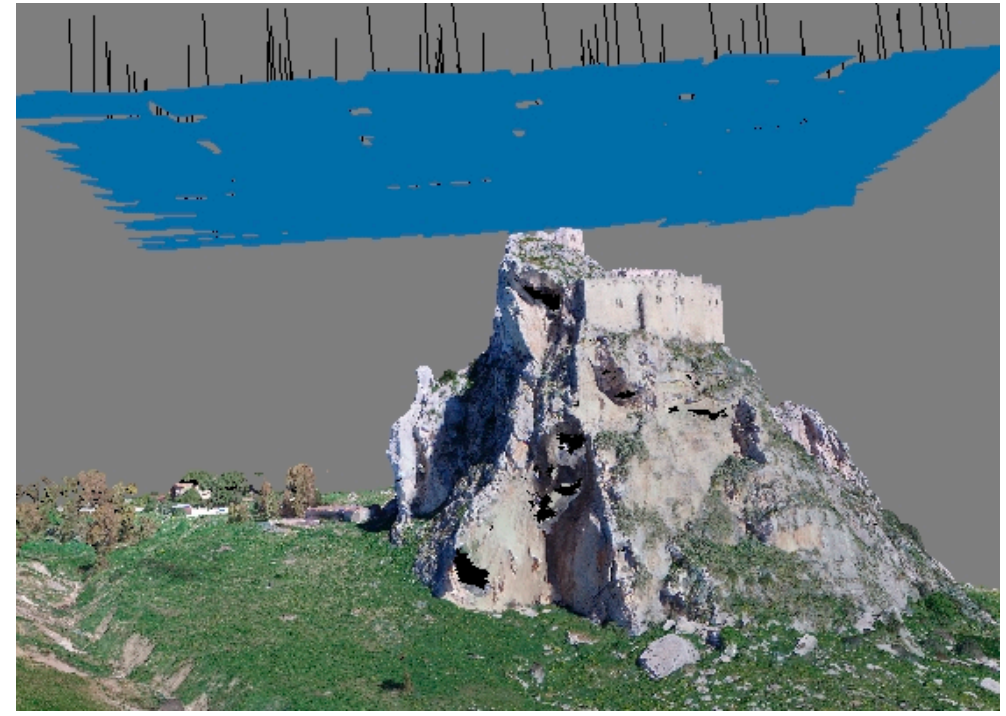

Figure 11. The 3D reconstruction of the outdoor environment from the UAV dataset.

\section{Generation of the Meshes and Matching of the Model}

The last phase of the workflow was the creation of the final 3D model of the monumental complex. During this phase, the aligned point clouds were triangulated to generate a 3D mesh of every represented environment. The $\mathrm{LoD}$ (Level of Detail) of the texture of every model was chosen by considering the extension of the surface recovered in the visualization.

The main reference model consists of the main outdoor shape of the castle, obtained with the support of the GNSS network. The other models of the indoor environments were matched with the main outdoor shape. In particular, the main outdoor shape was aligned with the other indoor 3D models by considering the correspondence between the main architectural elements like portals, walls, and windows, measured using direct survey operations.

The meshes were matched together using Blender ${ }^{\circledR}$, open-source 3D modelling software that allowed us to manage these matching operations, guaranteeing a good level of precision (Figure 12). 


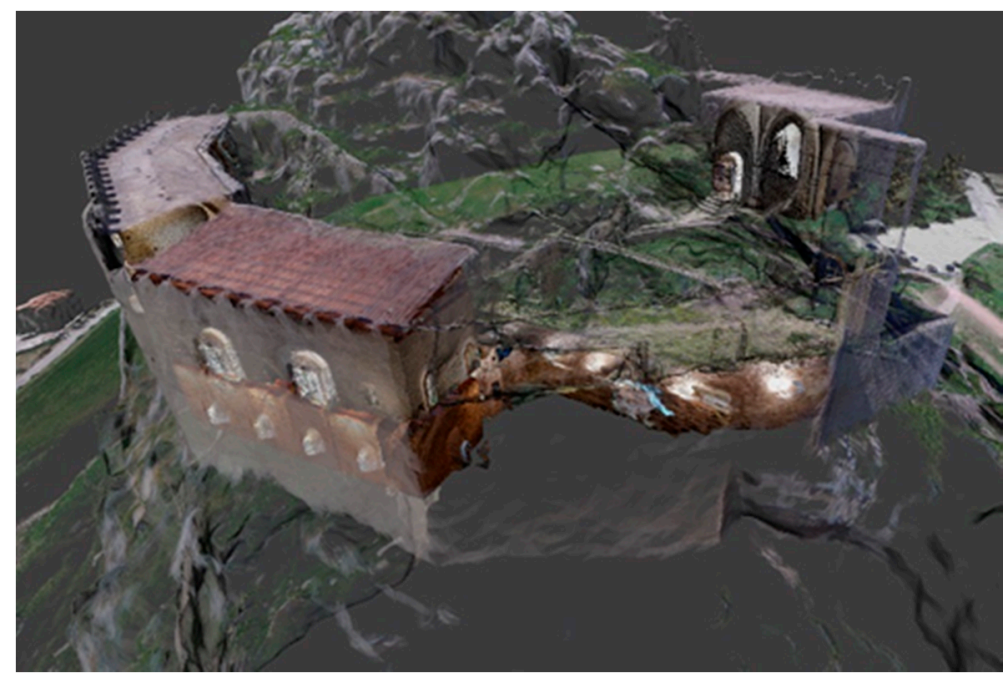

Figure 12. An outdoor view of the castle with the indoor environment seen in transparency.

The final matched model obtained at the end of these operations represented a complete virtual 3D reconstruction of the castle (outdoor and indoor) and the surrounding area, ready to be implemented as $3 \mathrm{D} \mathrm{CH}$ documentation.

This model was also exported to be freely navigable (Figure 13) on the web by connecting to the GISLab laboratory website at the following link: http://gislab.dirap.unipa.it/mussomeli/index.html.

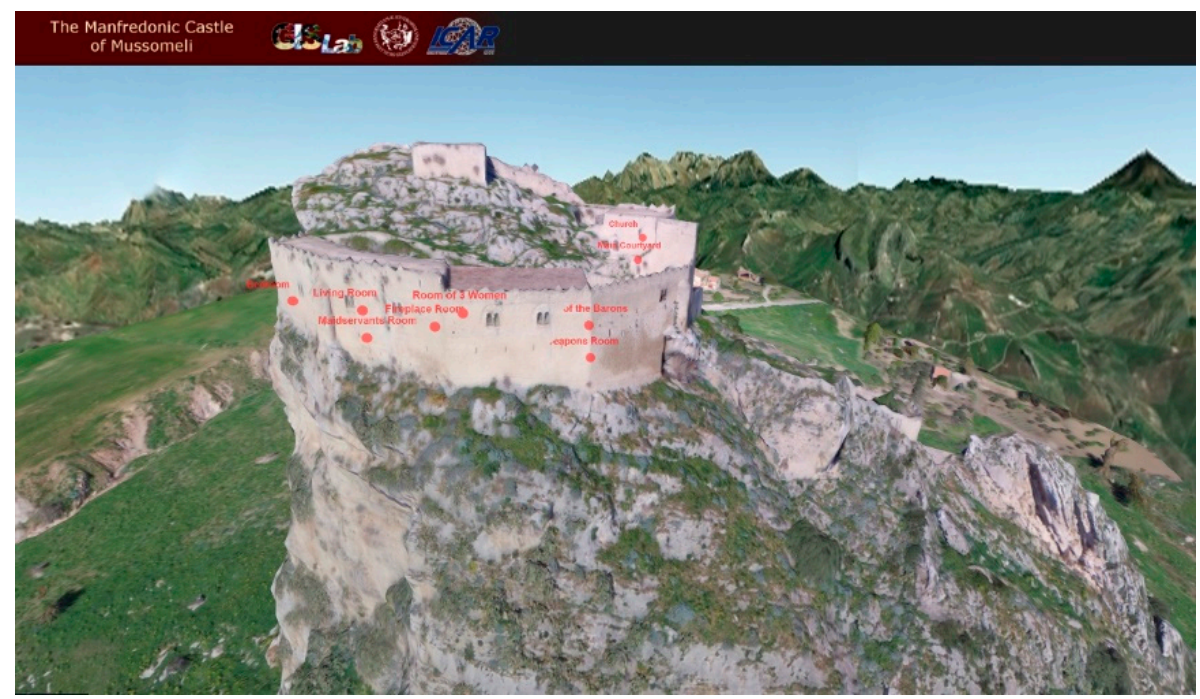

Figure 13. The 3D navigation model of the castle, navigable on the web.

\section{Comparison between the Obtained Results and Other Similar Study Cases}

The followed approach to the survey of the castle granted an exhaustive level of accuracy in the results towards the aim of the research, linked to sharing $\mathrm{CH}$ information. In order to verify the quality of the work, it is necessary to compare the obtained accuracy of the reconstruction with other similar cases.

One similar case which could be considered, as an example, is the survey and restitution of the Fornace Penna of Sampieri in Sicily (Italy). This work was developed for the benchmark 2017 activity organized by the Italian Society of Photogrammetry and Topography (SIFET). The studied cultural good was an interesting example of an industrial heritage building (Figure 14), and different survey options were pursued in a test area of $25 \times 30 \mathrm{~m}$ in plane [11]. In particular, considering the photogrammetric restitution obtained from UAV survey, the error obtained ranged between 4 and 
$6 \mathrm{~cm}$ when considering different blocks of flights executed at a distance between 10 and $25 \mathrm{~m}$ from the building surface using different cameras, with a GSD value of about $1 \mathrm{~cm}$ (depending on the distance between the camera and the surface and on the features of the sensor).

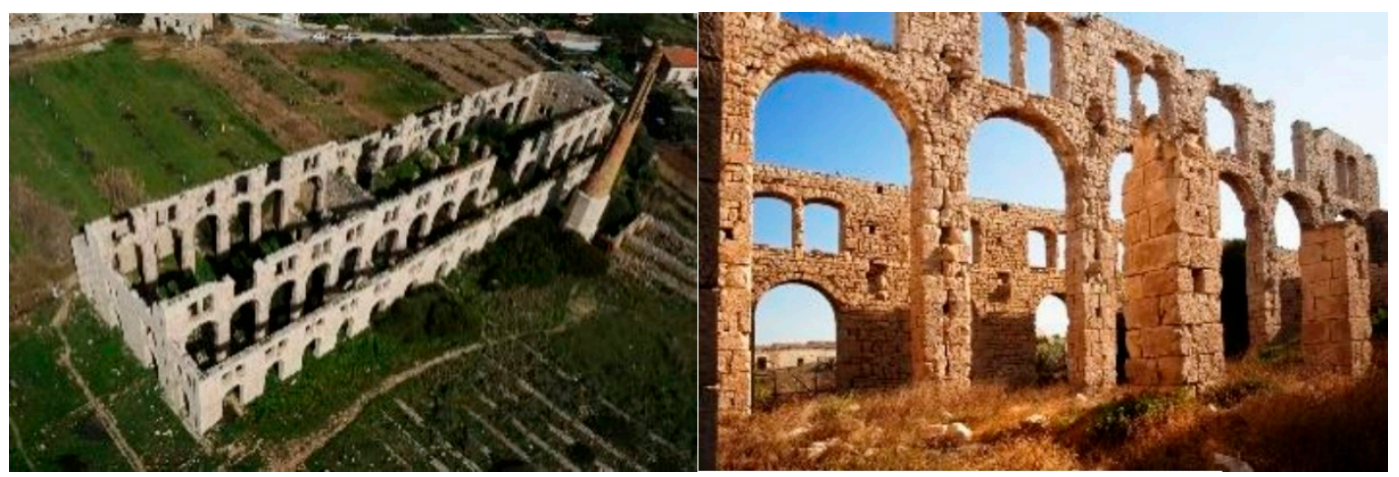

Figure 14. The Fornace Penna of Sampieri in Sicily (Italy) [11].

The reconstruction of the Chillon Castle in Switzerland was another similar case where a complete workflow was developed using Pix4Dmapper ${ }^{\circledR}$ (photogrammetric reconstruction software) [12]. In this case, different camera-lens combinations were tested in order to compare the obtained different results. The area of the castle consisted of a surface extended about $130 \times 60 \mathrm{~m}$ on plane. The error obtained from the results ranged between 2 and $8 \mathrm{~cm}$, depending on the kind of camera used.

In light of these examples, comparing the results in relation to the extension of the considered surface and the terrain conditions, the level of accuracy of the reconstruction of the Castle of Mussomeli is more than acceptable.

\section{Possibilities of 3D Documentation of $\mathrm{CH}$ Models}

The survey and the photogrammetric restitution of the castle of Mussomeli presented in this paper has illustrated a 3D model processing technique useful for different kinds of representation. It is possible to extrapolate orthophotos, section planes, or other restitution types that could improve knowledge on cultural goods. In recent times, new technologies in computer science have provided the possibility to create, starting from a 3D model, an interactive online representation of a cultural good with a reconstruction of the environment around it [13]. Furthermore, these technologies, together with the latest achievements obtained in photogrammetric restitution, allow the construction of a 3D GIS (Geographic Information System) environment accessible on the web [14]. To get these results and to load online 3D models of monumental complexes, it is also necessary substantially simplify the mesh, finding the right balance between the LoD and the speed of access on the web. Finally, the 3D model of the castle of Mussomeli was used for the creation of a 3D interactive navigation platform (Figure 15) available on the web [15]. 


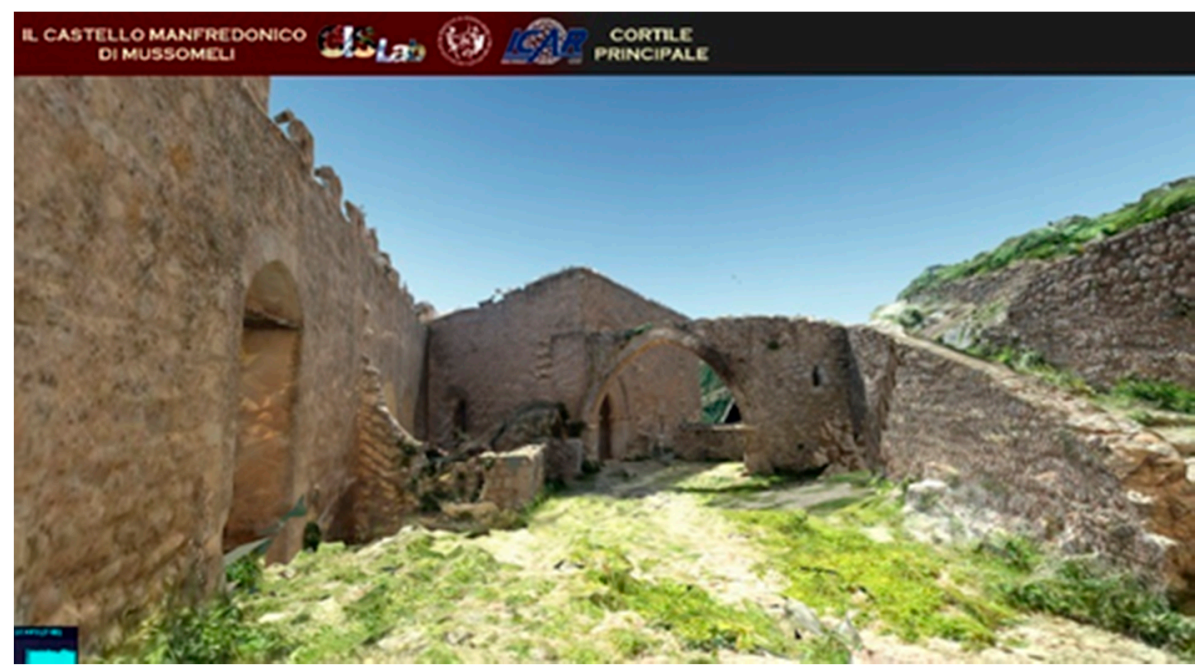

Figure 15. The main courtyard of the Castle of Mussomeli on the 3D web navigation platform.

\section{Conclusions and Future Developments}

The process described in this paper shows an example of how it is possible to produce a survey in a short time and then to generate photogrammetric restitution of a vast monumental complex positioned in an impervious area, strongly connected with the landscape around it. The LoD and precision on measurement obtained from this operation are not enough for monitoring the structures of the monument, but, at the same time, are enough for creating an exhaustive representative 3D model of the monumental complex, useful for the fruition and the diffusion of knowledge of the cultural good.

This model is also compliant for loading in 3D GIS online interactive applications, which are very useful for sharing $\mathrm{CH}$ 3D models on the web. Indeed, documentation and the digital fruition of a cultural good is a fundamental task to improve $\mathrm{CH}$ conservation [16].

Certainly, the positional accuracy of the survey could be increased by using a reference topographic network at the rock base level. However, in this case, the time involved in the survey operation would not be compatible with the goals of this valorization activity. The results of this experimentation could be considered a reference point for similar cases oriented toward the valorization of a cultural good. In the future, the workflow shown in this paper could represent a first step for the creation of a standard methodology of 3D documentation and digitalization of $\mathrm{CH}$ usable for any cultural good.

Author Contributions: Conceptualization, A.S. and M.L.; methodology, A.S. and M.L.; software, A.S. and M.L.; validation, A.S. and M.L.; formal analysis, A.S. and M.L.; investigation, A.S. and M.L.; resources, A.S. and M.L.; data curation, A.S. and M.L.; writing-original draft preparation, A.S. and M.L.; writing—review and editing, A.S. and M.L.; visualization, A.S. and M.L.; supervision, A.S. and M.L.

Funding: This research received no external funding.

Acknowledgments: Thanks to Geomax for making available the GNSS receiver "Zenith 35 Pro Tag" for carrying out the surveys of GCPs.

Conflicts of Interest: The authors declare no conflict of interest.

\section{References}

1. Mineo, S.; Pappalardo, G.; Mangiameli, M.; Campolo, S.; Mussumeci, G. Rockfall analysis for preliminary hazard assessment of the Cliff of Taormina Saracen Castle (Sicily). Sustainability 2018, 10, 417. [CrossRef]

2. McCarthy, J. Multi-image photogrammetry as a practical tool for cultural heritage survey and community engagement. J. Archaeol. Sci. 2014, 43, 175-185. [CrossRef]

3. Salonia, P.; Scolastico, S.; Pozzi, A.; Marcolongo, A.; Leti Messina, T. Multi-scale cultural heritage survey: Quick digital photogrammetric systems. J. Cult. Herit. 2009, 10S, e59-e64. [CrossRef] 
4. Siebert, S.; Teizer, J. Mobile 3D mapping for surveying earthwork projects using and Unmanned Aerial Vehicle (UAV) system. J. Archaeol. Sci. 2014, 41, 1-14. [CrossRef]

5. Vacca, G.; Dessì, A.; Sacco, A. The use of nadir and oblique UAV images for building knowledge. ISPRS Int. J. Geo-Inf. 2017, 6, 393. [CrossRef]

6. Smith, N.G.; Passone, L.; Al-Said, S.; Al-Farhan, M.; Levy, T.E. Drones in archaeology: Integrated data capture, processing, and dissemination in the al-ula valley, Saudi Arabia. Near East. Archaeol. 2014, 77, 176-181. [CrossRef]

7. Snavely, N.; Seitz, S.M.; Szeliski, R. Photo tourism: Exploring photo collections in 3D. ACM Trans. Graph. (TOG) 2006, 2, 835-846. [CrossRef]

8. Koutsoudis, A.; Vidmar, B.; Arnaoutoglou, F. Performance evaluation of a multi-image 3D reconstruction software on a low-feature artefact. J. Archaeol. Sci. 2013, 40, 4450-4456. [CrossRef]

9. Yastikli, N. Documentation of cultural heritage using digital photogrammetry and laser scanning. J. Cult. Herit. 2007, 8, 423-427. [CrossRef]

10. Dellaert., F.; Seitz, S.M.; Thorpe, C.E.; Thrun, S. Structure from Motion without Correspondence. Ph.D. Thesis, Carnegie Mellon University, Pittsburgh, PA, USA, 1999.

11. Piras, M.; Di Pietra, V.; Visintini, D. 3D modeling of industrial heritage building using COTSs system: Test, limits and performances. In Proceedings of the International Archives of the Photogrammetry, Remote Sensing and Spatial Information Sciences, Bonn, Germany, 4-7 September 2017; pp. 281-288. [CrossRef]

12. Strecha, C.; Zoller, R.; Ru-Tishauser, S.; Brot, B.; Schneider-Zapp, K.; Cho-Vancova, V.; Krull, M.; Glassey, L. Terrestrial 3D mapping using fisheye and perspective sensors. Available online: https:/ /www.researchgate. net/publication/272090366_ (accessed on 28 February 2019).

13. Scianna, A.; La Guardia, M.; Scaduto, M.L. Sharing on web 3D Models of Ancient Theatres. A Methodological Workflow. In Proceedings of the International Archives of the Photogrammetry, Remote Sensing and Spatial Information Sciences, Prague, Czech Republic, 12-19 July 2016; pp. 483-490. [CrossRef]

14. Scianna, A.; La Guardia, M. Main Features of a 3D GIS for a Monumental Complex with an Historical-Cultural Relevance. In Proceedings of the International Archives of the Photogrammetry, Remote Sensing and Spatial Information Sciences, Florence, Italy, 22-24 May 2017; pp. 519-526. [CrossRef]

15. Scianna, A.; La Guardia, M. Globe Based 3D GIS solutions for Virtual Heritage. In Proceedings of the International Archives of the Photogrammetry, Remote Sensing and Spatial Information Sciences, Delft, The Netherlands, 1-2 October 2018. [CrossRef]

16. Pieraccini, M.; Guidi, G.; Atzeni, C. 3D digitizing of cultural heritage. J. Cult. Herit. 2001, 2, 63-70. [CrossRef] 